\title{
The Impact of Information Technology on Information System Effectiveness in Jordanian Telecommunication Companies
}

\author{
Majd Al-Hawamdeh ${ }^{1}$, Shaker Alkshali ${ }^{1,2}$. \\ ${ }^{1}$ Jerash University, Jerash, Jordan \\ ${ }^{2}$ The world Islamic Sciences \& Education University, Amman, Jordan \\ Correspondence: Majd Al-Hawamdeh, Jerash University, Jerash, Jordan.
}

Received: January 9, 2020

Accepted: January 27, 2020

Online Published: January 31, 2020

doi:10.5539/cis.v13n1p90

URL: https://doi.org/10.5539/cis.v13n1p90

\begin{abstract}
This study aimed to test the impact of information technology on Information systems effectiveness in Jordanian Telecom Companies. The study adopted a five-dimensional scale to measure information technology (people, hardware, software, databases, and networks), while the information systems' effectiveness was measured through four dimensions: end-user satisfaction, system usage, system security and suitability of the system for management levels. To achieve study aims, a descriptive-analytical method was used. The study was conducted on a sample of (152) managers working in these companies. This study found that there is a high-level average for information technology dimensions and Information Systems effectiveness dimensions. Also, the results showed a significant impact of information technology dimensions (people, software, databases, and networks) except hardware on effectiveness information systems. It was also evident that there a significant impact of information technology on Information systems effectiveness dimensions (end-user satisfaction, system usage, system security and suitability of the system for management levels).
\end{abstract}

Keywords: information technology, information system effectiveness, Jordanian telecommunication companies

\section{Introduction}

An information system is a primary source for providing an organization with the appropriate information that it needs to carry out various activities and works (Maleszka, 2017). As information systems are a set of components that are linked to each other regularly to produce useful information, then sharing this information with users in a suitable form, time and help them to perform the assigned functions (Krenyácz, 2018). Information systems consist of five main processes, which are inputs: the set of data and raw materials to start the information processing steps, processes: the group of activities works to convert the raw materials (inputs) into useful information that helps in achieving systems goals (Pollák \& Tkáč, 2019), procedures: represents the method which used to implement a specific activity, outputs: the results of interaction between system components resulting from the process operations and finally feedback: the process of verifying the results and controlling their quality and evaluation (Yang et al., 2018). Information system effectiveness refers to the system contribution degree in achieving organizational goals, where the effectiveness means achieving planned and desired goals and is measured by comparing the achieved goals with the planned goals (Królikowski \& Susłow, 2017). Information technology and its various applications have a vital and important role in improving productivity of public or private organizations and achieving the desired goals (Li \& Fang, 2019), and it provides unprecedented opportunities in several areas such as improving job performance, decision-making process, facilitating and simplifying Procedures, the optimally use of the workforce, and its major contributions in the financial systems (Sánchez, 2018). Information technology has a set of components that are people whether end-user or technical specialists, databases, software, hardware and networks, and it aims to produce information that helps an organization in achieving goals (Martin, 2017).

\section{Theoretical Background}

\subsection{Information Technology}

Information technology represents a wide start of capabilities, components and various elements at all levels and fields that contribute in meeting the requirements of daily life, and business or various practical and scientific activities of organizations (Cardozo et al., 2019) and its three-dimensional mixture of computer systems, 
communication networks, and technology tools (Cheng et al., 2017). Sammicheli and Scaglione (2018) indicate to information technology as the group of discoveries, developments, and inventions that deal with all information in different size and deliver it to users at the appropriate time and form after modifying it with specific operations. Information technology is a system containing a set of interconnected and interacting resources and includes hardware, software, human resources, databases, networks, and communications. By combining these components, organizations can survive, thrive, and perform operations with high efficiency (Hsu et al., 2017). Because it has tools to receiving, processing, storing, retrieving, printing and transferring information electronically, in all forms text, audio, image or video through computers (Li \& Fang, 2019). Chernyshov and Filatova (2018) believes that information technology is devices, equipment, methods, and tools that person uses to obtain audio, video and digital information and to process that information in terms of recording, organizing, arranging, storing, possessing, retrieving, displaying, reproducing, broadcasting, and deliver it at suitable time for its seekers, which includes warehousing, retrieval and communication technology. As for Sánchez (2018), he pointed out that information technology is a set of modern methods and technologies that are used to simplify activities and raise their performance level (Néri et al., 2018). Thus, information technology was characterized by a set of features and characteristics, which is: -saving time and effort in obtaining information and transferring it to computer with high flexibility, the high accuracy in showing results and without errors, which enhance individuals skills and improving their knowledge, and creativity, -mobility in using and transferring databases, and applications in any place/time,- asynchronous in sending and receiving information or data at suitable time for the user, - ability to transfer and move information from one medium to another and from one type to another, such as converting an audio message to a printed message, -providing a group of operations and methodologies, -providing the necessary and important information and share it with decision-makers, -providing maintenance and safe handling of workers and customer files, -reducing the employee's burdens on their tasks, -controlling the access level of modifying, transferring and deleting, the information and data stored in databases, -facilitating the communication process between employees and business in fast and highly effective through many techniques (emails, video conferencing, chat rooms), -continuity in working without interruption or boredom (Piotrowicz \& Kedziora, 2019). There are many benefits that information technology provides to the organization including -boost organization productive efficiency, -enhance the competitive advantage, - boost organization's profitability, -re-engineering and organizing work, increase organization ability in the environment adapting, -enhance the organization ability to respond various environmental changes, -providing and analyzing the necessary information to perform various functions and planning activities,-improve the quality, and accuracy of information which provided to decision-makers, -reduce time and cost of transferring information and facilitate the process of storing and retrieving information, -documenting and processing information by computer and information technologies, -setting an appropriate system for storing, processing, and retrieving, preparing and presenting new information which helps in developing organization's infrastructure, -coordinating system efforts and cooperation with other systems, training and educating system users on optimal use of information (Iftikha et al., 2019). To measure information technology, our study relied on a five-dimensional scale, it will be discussed brevity.

1. People (human component): people are the most important component and the engine of information technology, directors of design and implementation processes, and the controllers of all other components. They educated and trained to dell up with modern technology, devices, and programs to achieve the desired benefit and goals. (Ramrathan \& Sibanda, 2017). There are two types of peoples the end-users or technical professionals: who are responsible for system operating and sustaining and each one has a special and specific function (Wensing et al., 2019).

2. Hardware: it set of devices and physical components used in entry activities, data processing operations, transmission and storage such as (computer devices, processing unit, input devices, output devices, storage devices, computer accessories, and physical media), that are used to link parts together, and the computer is the most important component of these devices (Burkov et al., 2018). These components include five physical parts: the central operating unit that works to adapt and transfer data and monitor other parts of the computer, the secondary storage unit that feeds the central operator with data and programs and stores them for needed use, the input devices which convert data from paper in electronic form, the output devices that transfer information from the computer to users and communication devices that monitor the communications between central operator and output devices, input devices, users (Sakhaei et al., 2017).

3. Software: the set of programs that enable the computer to enter data and process it to obtain results in an accurate and proper way and it consists of instructions, orders, and directions. Including operating systems groups that direct the physical components of computers and applied programs such as sales analysis software 
and word processing software. Physical components cannot perform their work without the software components (Ramrathan \& Sibanda, 2017).

4. Databases: a container of all stored, structured, and registered data and files on the computers, these files are the raw material that is processed, updated and retrieved to obtain accurate information easily (Yang et al., 2018). Lane et al. (2018) indicate the databases as the collection of logical elements and data linked to each other with mathematical relationships, which stored in the computer system to facilitate handling, searching, adding and modifying them.

5. Networks: the technical tools used to transfer data from one computer to another, which provides an opportunity to use all data located on all terminals and central computer, within organization boundaries (Albini et al., 2018), and its include several types like communications technology, long-term communication and other types of networks, such as the Internet and extranet. The network has become a necessity of business because it links organizations with the outside world and makes organizations a part of the global system (Carvalho et al., 2017). Shahdadi et al. (2017) define it as the links of two computers together through wired or wireless and this link allows the possibility share of files, printers, and other devices depend on the internet.

\subsection{Information Systems Effectiveness}

The information system performs a large variety of main functions and tasks such as collecting data through (registration, coding, classification, filtering, transferring), processing data in terms of (sorting, comparing, summarizing, calculating data), and producing information in terms of (preparing reports, sending reports, Broadcast report), manage information (storage, maintenance and retrieval of information), and finally data control and security (coding and monitoring this information) (Królikowski \& Susłow, 2017). Maleszka (2017) indicates that there are types of information systems, including manual information systems that rely on paper and pens for writing, and automated information systems that use computers, programs, networks and other information technology to convert data into information. Thus, there are several classifications of automated information systems, in terms of management level, or in job terms. Information systems are classified according to the management level of three types (Ada \& Ghaffarzadeh,2015): They are operational information systems levels that support operational managers and help them to carry out basic activities, commercial transactions, and follow-up of routine work, and middle-level information systems management that serve the monitoring and follow-up processes and take Decisions, actions and activities at the middle-level management and strategic levels information system assize managers in setting strategies, monitoring and addressing strategic issues inside and outside the organization. Krenyácz (2018) indicates that the effectiveness of information systems lies in the ability of these systems to generate outputs according to the required characteristics and the amount of the contribution of these outputs in facilitating the task of decision-making to achieves the users satisfaction, and also the effectiveness represents the actual achievement of goals and objectives by performing tasks at the required level, so implement the set plans, and that the set of work methods and policies which used to achieve tasks, must be consistent with the desired goals, and the accomplishing of goals within the specified dates and standards, with the lowest costs, also this systems must be able to detect negative and positive drift and the explain the reasons for these negative drift and present suggestions to support positive continuation of the performance and addressing the negative drift to avoid it in the future. The organization determines information system effectiveness according to returns and benefits that it achieves, but from the user viewpoint, it reflects system ability to provide correct, accurate and updated information that contributes to making effective decisions.

Measuring the level of effectiveness of information systems is not easy for small or big companies. In the past, large organizations have been able to measure the level of effectiveness because of their produced various services and activities and varied outputs in them, but small organizations with few activities have a problem in measuring the level of system effectiveness that used (Ada \& Ghaffarzadeh, 2015). Currently, corporate managers of all sizes use many new methods and standards to measure the information system's effectiveness, such as employee satisfaction measurement, and customer satisfaction measurement (Gorbatova et al., 2015). The process of measuring the information system effectiveness is complicated according to the difficulties that organizations face, such as environment rapid change and continuous development in the information technology, and it is difficult to measure the benefits and intangible costs of information systems and tracking the effects of information systems within the organization, therefore organizations used a set of methods and approaches to help in measure the Information systems effectiveness and determining the extent the ability of these systems to achieve the organization goals (Pollák \& Tkáč, 2019). Pavlov (2015) believes that there are five basic approaches that can be guided in determining the effectiveness of the system, namely: goal approach (outputs) that define effectiveness as the system supporter and through it the organization able to achieve the goals, it the 
most common approach in use, the resource approach (inputs) that determines effectiveness according to the system location in the external environment, the ecological approach (user satisfaction) that determines effectiveness according to the degree of benefit and interest presented to user and the degree to which the system meets the needs and expectations of user, the operations approach represents the effectiveness as a system internal process equivalent and the integrity of system processes and internal procedures, the social justice approach based on base of the seniority after classified users into categories. The level of information system effectiveness was determined by criteria: - total effectiveness: the competitiveness in achieving distinct goals and results within available capabilities, data and conditions, - productivity: the relation between the production elements which used to produce (goods or services) and the value of production in cash or tangible,- efficiency: the relation between inputs and outputs and attempting to reach largest amount of outputs with the lowest possible inputs, - profitability: reflects the achieved financial return from investing money or specific production elements, - quality: the level of quality and characteristics of provided product accordance specific standards, accidents: the rate of work injuries, - flexibility: the organization ability to cope, adaptation and fit with environmental changing (Fetaji et al, 2016). In this study, the following dimensions were adopted to measure the information system effectiveness:

1. End-user satisfaction: it's mean provide the end-user a necessary information at appropriate time, quantity, and quality, and this information must represent the actual fact, and reduce the ambiguity that faced the decision-maker, and easy to understand, use and gain the benefit of this information by end-users (Królikowski \& Susłow, 2017).

2. System Usage: the extent of users rely on the information outputs of information systems in performing their duties, tasks, and it measured by the frequency of use and the spent time of each use (Krenyácz, 2018).

3. System Security: the degree of accreditation of an information system on a set of security measures to protect all components of the system from theft, loss, and damage. These measures include: disallow unauthorized people to access the work and information of the system and don't leak information to unauthorized individuals (Pollák \& Tkáč, 2019), that can achieve by using a set of preventive measures in the management and technical levels to protect data sources from violations and unlawful interference (Fetaji et al., 2016).

4. The suitability of systems for management levels: ability of information system to provide information in a benefit from to help users according to their management level, generally or in details and keep this information close to users who need it so to utilize the working time (Pollák \& Tkáč, 2019).

\subsection{Relation Between Information Technology and Information Systems}

The relation between information technology and information systems that information technology is the means and tools which facilitate the work of the information system and enable it to perform its functions (Gorbatova et al., 2015), where information systems are defined as a set of procedures that deal with data and information and perform many operations on these data such as enter, store, process, Retrieve, publish and broadcast using various electronic means (Burkov et al., 2018). Thus, information technology becomes a basic requirement enabling organizations to carry out their various operations efficiently and quality, and enabling them to activate their systems, through the provided capabilities of information technology, which is information capabilities, knowledge capabilities that help organizations to survive, continue and grow (Wensing et al., 2019). Therefore, the organization must prepare all the requirements to exploit information technology and the new technological means that may open up wide areas and opportunities towards new markets to organizations through various means, including training programs, bringing experts, foreign employment, joint ventures, contracts (Piotrowicz \& Kedziora, 2019). Also, relation between information technology and information systems is an integral, reciprocal and cooperative relation as information systems are a set of systems and programs used in archiving and managing data and information through collecting, staggering, listing, recording, obtaining and protecting outputs according to specific procedures that are established depending on the workflow mechanism in the organization and from then made it available to the right person at the right time and the importance of information systems lies in serving decision-makers in making optimal management decisions. As for information technology, it's the set of innovations and creative techniques used to realize success for all activities and processes and ensuring the system's effectiveness, therefore information technology is the tool that is used to realize the information system effectiveness through a set of new technologies that have been created in the world of technology.

Both information system and information technology deal with computer-based systems, but both require different education and training. Information technology is a subset of information systems and information system is the cover of all sub-information groups. Information technology refers to the technological part of that 
system. The two concepts are related to each other but they have distinct sets of characteristics. Information systems act as a bridge between technology and individuals, while Information technology and its technics focus on helping the information system and the people (who use system) to understand this system.

\subsection{Hypothesis}

According to the theoretical framework of study variables (information technology and information system effectiveness) and indicating the logical relation between them, researchers can adopt the following hypotheses:

H1: There is a significant impact of information technology on information system effectiveness in Jordanian Telecommunication Companies.

H2: There is a significant impact of information technology on the end-user satisfaction in Jordanian Telecommunication Companies.

H3: There is a significant impact of information technology on System Usage in Jordanian Telecommunication Companies.

H4: There is a significant impact of information technology on system security in Jordanian Telecommunication Companies.

H5: There is a significant impact of information technology on system suitability for management levels in Jordanian Telecommunication Companies.

\section{Method}

\subsection{Research Methodology}

This study is designed to determine the impact of information technology on Information systems effectiveness in Jordanian Telecom Companies. The study follows sequential procedures as a strategy for the mixed methods that have been applied. The researchers collect qualitative data that are quantitatively analyzed. The study is exploratory in trying to reveal the possible impact of IT on information systems effectiveness, but analytical in drawing the conclusion. The results of the hypotheses test are analyzed, and the implication of hypotheses is determined to reach recommendations and conclusions. The researcher reviews the theoretical studies and researches to crystallize the foundations on which the theoretical framework is based. A questionnaire is used to achieve the purpose of the study.

\subsection{Sample}

The population of this study consisted of all managers in Jordanian telecommunications companies, and there are (3) companies with (336) managers work in, and the researchers adopted the questionnaire to collect data from these managers with a proportional random sample whose size reached (181) managers according to sample table (Sekaran \& Bougie, 2012). Where (83) questionnaires were distributed to managers in Orange Company, (62) questionnaires to managers in Zain Company, and (36) questionnaires to managers in Umniah Company. A (152) questionnaires valid for analysis were retrieved, which constitutes (84\%) of sample size.

\subsection{Measurements}

To measure the information technology (independent variable), researchers used a scale of these studies (Manaseer et al, 2019) \& (Rahmani \& Rahmani, 2016). consisting of five dimensions: people, hardware, software, databases and networks has been used. The number of items of scale reached (25) items distributed by (5) items for each dimension as in table (1). For measuring information system effectiveness (dependent variable), researchers used a scale of four dimensions contained in study (Tawfiq, 2019): the end-user satisfaction, the system usage, system security and suitability of systems for management levels. The number of items of this scale reached (24) items distributed by (6) items for each dimension as in table (1).

The answer for each scale was determined according to the five-digit scale, which is strongly agreed (5) points and strongly disagreed by (1) point. The scale reliability was tested and it found all of them exceeded (0.70), which indicates their reliability. 


\subsection{Statistical Analysis}

Table 1. Reliability and descriptive analysis

\begin{tabular}{|ccccc|}
\hline Dimension & Items & Alpha & Mean & Std. \\
\hline People & 5 & 0.857 & 3.837 & 0.741 \\
\hline Hardware & 5 & 0.796 & 4.106 & 0.539 \\
\hline Software & 5 & 0.885 & 3.751 & 0.893 \\
\hline Databases & 5 & 0.819 & 3.694 & 0.682 \\
\hline Networks & 5 & 0.772 & 3.481 & 0.952 \\
\hline End user Satisfaction & 6 & 0.901 & 3.941 & 0.683 \\
\hline System Usage & 6 & 0.849 & 3.749 & 0.688 \\
\hline System Security & 6 & 0.802 & 4.194 & 0.841 \\
\hline suitability of systems for management levels & 6 & 0.748 & 4.006 & 0.770 \\
\hline
\end{tabular}

Table (1) indicates the results of Cronbach's Alpha Coefficient test for study items, where the reliability degrees exceeding the permissible limits which are (\%0.70) for their approval of statistical analysis (Sekaran \& Bougie, 2012) according to test results. Also, table (1) shows the results of descriptive analysis (mean and standard deviation) of study items, where the study sample (managers) indicate that their companies provide the hardware in a high degree for information technology, and the mean average value of this dimension items reached (4.106) and less than this dimension is for the people with mean average value (3.8837), followed by software with an mean average value $(3,751)$, then databases with an average value $(3,694)$ and the last interest for networks with an mean average value $(3,481)$. As for the dimensions of information system effectiveness, test results found that system security has the highest importance with mean average value (4.194) and in the second degree to the suitability of system for management levels with mean average value (4.006), followed by the end-user satisfaction with average value (3.941) and finally, the system usage with mean average value (3.749) and all of them are high.

H1: There is a significant impact of information technology on information system effectiveness in Jordanian Telecommunication Companies.

Table 2. Impact of information technology on information systems effectiveness

\begin{tabular}{|ccccc|}
\hline Dimension & B & Beta & T & Sig. \\
\hline People & 0.101 & 0.125 & 1.842 & $\mathbf{0 . 0 3 7}$ \\
\hline Hardware & 0.056 & 0.078 & 1.185 & $\mathbf{0 . 2 3 8}$ \\
\hline Software & 0.128 & 0.177 & 2.504 & $\mathbf{0 . 0 1 4}$ \\
\hline Databases & 0.112 & 0.148 & 2.192 & $\mathbf{0 . 0 2 4}$ \\
\hline Retworks & 0.506 & 0.638 & 10.873 & $\mathbf{0 . 0 0 0}$ \\
\hline & & $\mathbf{R}^{2}=\mathbf{0 . 6 4 6}$ & & F =0.48.547 \\
Sig.=0.000 \\
\hline
\end{tabular}

Table (2) indicates the results of multiple regression analysis for the impact of information technology on information systems in Jordanian Telecommunications Companies, where the value of the correlation coefficient was $(\mathrm{R}=0.804)$ and this indicates a relation between information technology and information system effectiveness. While the value of $\mathrm{R}^{2}$ was $\left(\mathrm{R}^{2}=0.646\right)$, this means that information technology explained $(64.6 \%)$ of the variance in the information system effectiveness, and the value of $F$ was (48.547) at the level of significance $(\mathrm{Sig}=0.000)$, which indicates the significant impact of information technology on information system effectiveness. Also, table (2) shows that is a high impact for dimensions of information technology: networks, software, databases and people in leading the information system effectiveness respectively in terms to it impact, as the value of $\mathrm{B}$ for these dimensions was $(\mathrm{B}=0.505,0.128,0.112,0.101)$ and $\mathrm{T}$ value was $(\mathrm{T}=10.873$, $2.504,2.192,1.842$ ), at the significant level. (Sig. $=0,000,0.014,0.024,0.037)$. Whereas, the hardware dimension doesn't have a significant impact on information system effectiveness, as it reached $\mathrm{B}$ value $(\mathrm{B}=0.056)$ and $\mathrm{T}$ value was $(\mathrm{T}=1.185)$ at the level of significant $(\mathrm{Sig} .=0.238)$ which means these no significant effects of it. According to the results of the multiple regression analysis, the first hypothesis can be accepted.

$\mathrm{H} 2$ : There is a significant impact of information technology on the end-user satisfaction in Jordanian Telecommunication Companies.

Table 3. Impact of information technology on end-user satisfaction

\begin{tabular}{|ccccc|}
\hline $\mathbf{R}$ & $\mathbf{R}^{2}$ & $\mathbf{B}$ & $\mathbf{F}$ & Sig. \\
\hline $\mathbf{0 . 6 4 9}$ & 0.421 & 0.793 & 228.358 & 0.000 \\
\hline
\end{tabular}

Table (3) indicates the results of the simple regression of information technology impact on the end-user satisfaction. It found that there is a relation between the two variables, where the value of correlation coefficient 
$R$ was $(R=0.649)$ while the value of $R^{2}$ was $\left(R^{2}=0.421\right)$, which means that the information technology explained an amount $(24.1 \%)$ of the variation in the end-user satisfaction. Also, the value of $F$ was $(F=228.358)$ and the level of significance was $(\mathrm{Sig} .=0.000)$, which indicates a significant impact of information technology on end-user satisfaction in Jordanian telecommunication Companies. According to the results of simple regression analysis, the second hypothesis can be accepted.

H3: There is a significant impact of information technology on System Usage in Jordanian Telecommunication Companies.

Table 4. Impact of information technology on the system $u$

\begin{tabular}{|ccccc|}
\hline $\mathbf{R}$ & $\mathbf{R}^{2}$ & $\mathbf{B}$ & $\mathbf{F}$ & Sig. \\
\hline $\mathbf{0 . 6 2 1}$ & 0.386 & 0.743 & 202.451 & 0.000 \\
\hline
\end{tabular}

Table (4) indicates the results of the simple regression of the impact of information technology on the system usage, as it was found that there is a relation between the two variables, where the value of the correlation coefficient $R$ was $(R=0.621)$ while the value of $R^{2}$ was $\left(R^{2}=0.386\right)$, this means that the information technology explained an amount (38.6\%) of the variance in the system usage. The value of $\mathrm{F}$ was $(\mathrm{F}=202.451)$ and the level of significance was (Sig. $=0.000$ ), which indicates a significant impact of information technology on the system usage of the information systems in Jordanian Telecommunication Companies. According to the results of the simple regression analysis, the third hypothesis can be accepted.

H4: There is a significant impact of information technology on System Security in Jordanian Telecommunication Companies.

Table 5. Impact of information technology on system security

\begin{tabular}{|ccccc|}
\hline $\mathbf{R}$ & $\mathbf{R}^{2}$ & $\mathbf{B}$ & $\mathbf{F}$ & Sig. \\
\hline $\mathbf{0 . 5 2 5}$ & 0.276 & 0.584 & 119.505 & 0.000 \\
\hline
\end{tabular}

Table (5) indicates the results of the simple regression of the impact of information technology on system security, as it was found that there is a relation between the two variables. where the value of the correlation coefficient $R$ was $(R=0.525)$ while the value of $R^{2}$ was $\left(R^{2}=0.276\right)$, this means that the information technology explained an amount (\%27.6) of the variance in system security, also the value of $F$ was $(\mathrm{F}=119.505)$ and the level of Sig. was $(\mathrm{Sig} .=0.000)$, which indicates a significant effect of information technology in the system security of Jordanian Telecommunications Companies. Therefore, the fourth hypothesis can be accepted.

H5: There is a significant impact of information technology on system suitability for management levels in Jordanian Telecommunication Companies.

Table 6. Impact of information technology on system suitability for management levels

\begin{tabular}{|ccccc|}
\hline $\mathbf{R}$ & $\mathbf{R}^{2}$ & $\mathbf{B}$ & $\mathbf{F}$ & Sig. \\
\hline $\mathbf{0 . 5 9 7}$ & 0.356 & 0.783 & 173.665 & 0.000 \\
\hline
\end{tabular}

Table (6) indicates the results of the simple regression of the impact of information technology on the system suitability for management levels. It was found that there is a relation between the two variables, where the value of correlation coefficient $R$ was $(R=0.597)$ while the value of $R^{2}$ was $\left(R^{2}=0.356\right)$, which means that information technology has been explained an amount $(35.6 \%)$ of the variance in the system suitability for management levels. The value of $\mathrm{F}$ was $(\mathrm{F}=173.665)$ and the level of significance was $(\mathrm{Sig} .=0.000)$, which indicates a significant impact of information technology on the system suitability for management level. Depending on the results of the analysis, the fifth hypothesis can be accepted.

\section{Conclusion}

This study focused on examining the impact of information technology on effectiveness of information systems in Jordanian Telecommunication Companies. The results of descriptive analysis indicated that there are high levels of dimensions of information technology with the except hardware, this indicates the management departments concern of these companies' in providing they need from the technological requirements, in particular, the hardware components such as computers, input devices, processing units, and output devices, which are under the rapid development, In addition, the high concern on people, which is the main driver of all information technology components, and the controls of other components, also the Jordanian Telecommunications Companies attach a great importance to training their employees to train as specialists who are able to use and maintain systems as their activity needs. It was also found that the Jordanian Telecommunications Companies have effective information systems with a high degree of security, capable of serving all administrative levels, which is reflected positively in the end-user satisfaction about the system and leads to repeated use for the system. 
This study also indicate that there a significant impact of the information technology and its dimensions on the information system effectiveness (people, software, databases and networks), except the hardware, where the availability of people and software and the existence of databases can be used on internal and global networks increases the effectiveness of information systems. Furthermore, results found that the information technology has a significantly impacts in all dimensions of the information systems effectiveness, where the use of modern, advanced and integrated information technology increases the end-user satisfaction, which leads to the repeated use of the system, and increases the system security, also provides the necessary information for the different administrative levels.

\section{References}

Ada, Ş., \& Ghaffarzadeh, M. (2015). Decision making based on management information system and decision support system. European Researcher, 93(4), 260-269. https://doi.org/10.13187/er.2015.93.260

Albini, A., Tokody, D., \& Rajnai, Z. (2018). The Categorization and information technology security of automated vehicles. Interdisciplinary Description of Complex Systems, 16(3-A), 327-332. https://doi.org/10.7906/indecs.16.3.4

Burkov, V. N., Burkova, I. V., Rossikhina, L. V., \& Meshcheryakova, T. V. (2018). Information technologies for development management systems. Automation and remote control, 79(10), 1813-1822. https://doi.org/10.1134/S0005117918100065

Cardozo, C. T., Filho, O. R. K., \& Vaccaro, G. L. R. (2019). Keep innovating: Absorptive capacity and the performance of Brazilian information technology companies. Journal of Contemporary Administration, 23(4), 499-519. https://doi.org/10.1590/1982-7849rac2019180221

Carvalho, V. D. H. D., Poleto, T., \& Seixas, A. P. C. (2017). Information technology outsourcing relationship integration: A critical success factors study based on ranking problems (P. $\gamma$ ) and correlation analysis. Expert Systems. https://doi.org/10.1111/exsy.12198

Cheng, X. S., Yan, X. B., \& Bajwa, S. B. (2017). Exploring the emerging research topics on information technology-enabled collaboration for development. Information Technology for Development, 23(3), 403-414. https://doi.org/10.1080/02681102.2017.1363070

Chernyshov, O. O., \& Filatova, T. V. (2018). Features of the development of social projects using information technology. Informatics and Mathematical Methods in Simulation, 8(3), 238-244.

Fetaji, B., Fetaji, M., Jashari, X., Ebibi, M., Ljajic, S., Kamberovic, H., \& Iseini, B. (2016). Assessing and evaluating UBT model of student management information system using ANOVA. TEM Journal, 5(3), 313-318. https://doi.org/10.1109/MECO.2016.7525780

Gorbatova, L. V., Oleinikova, A. V., Sadanova, B. M., \& Mukhasheva, G. S. (2015). Automation of Methods for the Subjective Measuring of Factors in the Operation of Automated Information Systems by Means of VBA. European Researcher, 90(1), 26-31. https://doi.org/10.13187/er.2015.90.26

Hsu, C. L., Chen, M. C., \& Lin, Y. H. (2017). Information technology adoption for sustainable development: Green e-books as an example. Information Technology for Development, 23(2), 261-280. https://doi.org/10.1080/02681102.2017.1298078

Iftikha, S., Saqib, A., Sarwar, M. R., Sarfraz, M., Arafat, M., \& Shoaib, Q. (2019). Capacity and willingness to use information technology for managing chronic diseases among patients: A cross-sectional study in Lahore, Pakistan. PLOS ONE. https://doi.org/10.1371/journal.pone.0209654

Krenyácz, É. (2018). Use of management information in hospital Decision-making. Budapest Management Review, 5, 2-12. https://doi.org/10.14267/VEZTUD.2018.05.01

Królikowski \& Susłow. (2017). The management information system concept for domestic tour operator. Studies \& Proceedings of Polish Association for Knowledge Management, 86, 24-39.

Lane, R., Follett, K., \& Lindsay, J. (2018). Unsustainable trajectories of domestic information technology use in Australia: Exploring diversity and the life course. The Geographical Journal, 184, 357-368. https://doi.org/10.1111/geoj.12260

Li, R., \& Fang, W. H. (2019). University-industry-government relations of the Ministry of Industry and Information Technology (MIIT) universities: The perspective of the mutual information. PLOS ONE. 1-14. https://doi.org/10.1371/journal.pone.0211939

Maleszka, B. (2017). A method for determining ontology-based user profile in document retrieval system. 
Journal of Intelligent \& Fuzzy Systems, 32(1), 1253-1263. https://doi.org/10.3233/JIFS-169124

Manaseer, M., Maqableh, M., Alrowwad, A., \& Masa'deh, R. (2019). Impact of Information Technology on Organizational Performance in Jordanian Public Entities. Jordan journal of business administration, 15(4), 489-516.

Martin, S. (2017). Real and potential influences of information technology on outdoor recreation and wilderness experiences and management. Journal of Park and recreation administration, 35(1), 98-101.

Néri, E. D. R., Woods, D. J., \& Fonteles, M. M. D. F. (2018). Assessment of knowledge, skills and attitudes in the use of information technology to support hospital pharmacists clinical practice: Development and validation of a questionnaire. Journal of Young Pharmacists, 10(4), 439-443. https://doi.org/10.5530/jyp.2018.10.96

Pavlov, I. (2015). Evaluating methods of the project solution effectiveness in information security system developing based on resource maps. Informatics and Mathematical Methods in Simulation, 5(1), 10-18.

Piotrowicz, W., \& Kedziora, D. (2019). Outsourcing of information technology and business processes in Poland: Motivations and environmental factors. Managing Global Transitions, 16(4), 307-333. https://doi.org/10.26493/1854-6935.16.307-333

Pollák, M., \& Tkáč, J. (2019). Enterprise information data management system for small manufacturing company. TEM Journal, 8(4), 1169-1175.

Rahmani, S., \& Rahmani, M. (2016). The Role of E-management in the Process of Planning: A Field Study for Condor Electronics Bordj Bou. Ru'á Iqtișadīyah, 265(4163), 1-11.

Ramrathan, D., \& Sibanda, M. (2017). The impact of information technology advancement on intuition in organisations: A phenomenological approach. The Journal of Developing Areas, 51(1), 207-221. https://doi.org/10.1353/jda.2017.0012

Sakhaei, S., Motaarefi, H., Zinalpoor, S., \& Sadagheyani, H. E. (2017). Utilizing the information and communication technology as a learning tool for students. Annals of Tropical Medicine and Public Health, 10(5), 1189-1194. https://doi.org/10.4103/ATMPH.ATMPH_325_17

Sammicheli, M., \& Scaglione, M. (2018). Information technology as a tool for the Italian Institute of Social Security (INPS) in the management of social security and civil disability: Pro and cons. Technology and Health Care, 26, 343-347. https://doi.org/10.3233/THC-171151

Sánchez, J. M. (2018). The information technology revolution and the unsecured credit market. Economic Inquiry, 56(2), 914-930. https://doi.org/10.1111/ecin.12519

Sekaran, U., \& Bougie, R. (2012). Research methods for business: A skill building approach (6th ed.). New York, NY: John Wiley \& Sons Inc.

Shahdadi, H., Yazdanpenah, A., \& Ghavam, A. (2017). Investigate the relationship between information technology and employees' productivity with mediating role of knowledge management (Case study: Imam Reza Hospital of Sirjan). World Family Medicine/Middle East Journal of Family Medicine, 15(6). 55-64. https://doi.org/10.5742/MEWFM.2017.92984

Tawfiq, A. Z. (2019). Re-engineering Management Information Systems and Its Effect on Their Effectiveness: An Exploratory Study of A Sample of Miss End Users, Mosul University. Journal tnmeat alrafeddn, 38(121), 155-170. https://doi.org/10.33899/tanra.2019.161168

Wensing, M., Paech, B., Roth, C., \& Schwill, S. (2019). Learning, understanding and the use of information technology: A survey study among primary care physician trainees. BMC Health Services Research. https://doi.org/10.1186/s12913-019-4615-y

Yang, Z. H., Wang, Y. W., \& Sun, C. S. (2018). Emerging information technology acceptance model for the development of smart construction eystem. Journal of Civil Engineering and Management, 24(6), 457-468. https://doi.org/10.3846/jcem.2018.5186

\section{Copyrights}

Copyright for this article is retained by the author(s), with first publication rights granted to the journal.

This is an open-access article distributed under the terms and conditions of the Creative Commons Attribution license (http://creativecommons.org/licenses/by/4.0/). 